\title{
DEVELOPMENT AND ASSESSMENT OF COATINGS FOR FUTURE POWER GENERATION TURBINES
}

\author{
M. A. Alvin \\ U.S. DOE National Energy Technology Laboratory \\ Pittsburgh, PA 15236, USA \\ K. Klotz and B. McMordie \\ Coatings for Industry, \\ Souderton, PA 18964, USA \\ B. Gleeson \\ University of Pittsburgh \\ Pittsburgh, PA 15261, USA
}

\author{
D. Zhu \\ NASA Glenn Research Center \\ Cleveland, OH 44135, USA \\ B. Warnes \\ Corrosion Control Consultants, Inc. \\ Beaver, PA 15009, USA \\ B. Kang and J. Tannenbaum \\ West Virginia University \\ Morgantown, WV 26506, USA
}

\begin{abstract}
The NETL-Regional University Alliance (RUA) continues to advance technology development critical to turbine manufacturer efforts for achieving DOE Fossil Energy (FE's) Advanced Turbine Program Goals. In conjunction with NETL, Coatings for Industry (CFI), the University of Pittsburgh, NASA GRC, and Corrosion Control Inc., efforts have been focused on development of composite thermal barrier coating (TBC) architectures that consist of an extreme temperature coating, a commercially applied 7-8 YSZ TBC, a reduced cost bond coat, and a diffusion barrier coating that are applied to nickel-based superalloys or single crystal airfoil substrate materials for use at temperatures $\geq 1450^{\circ} \mathrm{C}\left(\geq 2640^{\circ} \mathrm{F}\right)$. Additionally, construction of a unique, high temperature $\left(\sim 1100^{\circ} \mathrm{C} ; \sim 2010^{\circ} \mathrm{F}\right)$, bench-scale, micro-indentation, nondestructive (NDE) test facility at West Virginia University (WVU) was completed to experimentally address in-situ changes in TBC stiffness during extended cyclic oxidation exposure of coated single crystal coupons in air or steamcontaining environments. The efforts and technical accomplishments in these areas are presented in the following sections of this paper.
\end{abstract}

\section{INTRODUCTION}

Gas turbines are the workhorse of power generation systems, and current land-based engine technology advancements are linked directly to our country's economy and energy security.
Technical advancement for any type of gas turbine generally implies better performance, greater efficiency and extended component life. From the standpoint of cycle efficiency and durability, this suggests that a continual goal for higher gas turbine-inlet-temperatures (TITs) with reduced levels of coolant is desirable. Realization of future high-efficiency, near-zero emission turbine power systems depends critically on the advancement of thermal protection of hot sections, such as the first stage vanes and blades, and control of secondary flows. Current technology for protecting such airfoils relies primarily on the combined effects of thermal barrier coatings (TBCs) and convective cooling. However, the state-of-the-art (SOTA) development in both TBC materials and cooling technologies is insufficient to meet the thermal-mechanical demands imposed by the hot gas with elevated TITs. This overall suggests that significant advances in TBC performance and durability and turbine cooling effectiveness must be achieved.

Current coal-fired Integrated Gasification Combined Cycle (IGCC) plant operating efficiencies range between $35-45 \%$. DOE FE's goals are targeting plant efficiencies of $45-50 \%$ at $<\$ 1000 / \mathrm{kw}$, with near zero-emissions including $\mathrm{CO}_{2}$ with multi-product production (i.e., electricity and hydrogen). The DOE FE goals for advanced hydrogen-fired turbines are 3-5 percentage points above a 7FA engine. Technology developers have performed systems analyses using proprietary data and

This material is declared a work of the U.S. Government and is not subjected to copyright protection in the United States. Approved for public release; Distribution is unlimited. 
advanced modeling capabilities, predicting that designs stemming from their R\&D efforts will exceed this goal [1].

While improvements to turbine efficiencies may be achieved by the use of recuperation to preheat the air entering the combustor, improved sealing and clearance control technology and improved steam cycles, the largest efficiency gains are believed to be achieved by increasing the engine inlet temperature. By using closed-loop steam cooling in place of compressor discharge air, current $\mathrm{H}$-series gas turbines that were developed under the Advanced Turbine Systems (ATS) program are able to increase inlet operating temperatures from $\sim 1260^{\circ} \mathrm{C}\left(\sim 2300^{\circ} \mathrm{F}\right)$ to $\sim 1425^{\circ} \mathrm{C}\left(\sim 2600^{\circ} \mathrm{F}\right)$, making better use of available compressor air.

Future advanced hydrogen-fired and oxy-fuel turbines that are now being designed to meet DOE FE's goals will experience an enormous level of thermal and mechanical loading as TITs approach $\sim 1425-1760^{\circ} \mathrm{C} \quad\left(\sim 2600-3200^{\circ} \mathrm{F}\right.$; Table 1) [2]. Currently there is no commercially available functional metallic-based system that can maintain a reasonable level of compositional and microstructural stability for prolonged exposure above temperatures of $\sim 1050^{\circ} \mathrm{C}\left(\sim 1920^{\circ} \mathrm{F}\right)$. Alloys for high temperature applications are often protected from surface degradation by either an overlay or a diffusion coating that contains the $\beta$-NiAl phase as a primary constituent [3]. Such $\beta$-containing coatings have a sufficiently high aluminum content to form a continuous scale layer of the slow growing and highly stable oxide $\mathrm{Al}_{2} \mathrm{O}_{3}$ at both intermediate (700$\left.1000^{\circ} \mathrm{C} ; \sim 1290^{\circ}-1830^{\circ} \mathrm{F}\right)$ and high $\left(>1000^{\circ} \mathrm{C} ; \sim 1830^{\circ} \mathrm{F}\right)$ temperatures. The thermally grown oxide (i.e., TGO: $\mathrm{Al}_{2} \mathrm{O}_{3}$ ) serves as an effective barrier, protecting the coated component from the process environment.

Table 1 - Advanced Turbine Operating Conditions [2]

\begin{tabular}{|c|c|c|c|c|}
\hline & $\begin{array}{c}\text { Syngas } \\
\text { Turbine } \\
2010\end{array}$ & $\begin{array}{c}\text { Hydrogen } \\
\text { Turbine } \\
2015\end{array}$ & $\begin{array}{c}\text { Oxy-Fuel } \\
\text { Turbine } \\
2010\end{array}$ & $\begin{array}{c}\text { Oxy-Fuel } \\
\text { Turbine } \\
2015\end{array}$ \\
\hline $\begin{array}{c}\text { Combustor } \\
\text { Exhaust Temp, }{ }^{\circ} \mathrm{C}\end{array}$ & $\geq 1480$ & $\geq 1480$ & & \\
\hline $\begin{array}{c}\text { Turbine Inlet } \\
\text { Temp, }{ }^{\circ} \mathrm{C} \\
\end{array}$ & $\sim 1370$ & $\sim 1425$ & $\sim 620$ & $\begin{array}{l}760 \text { (HP) } \\
\sim 1760 \text { (IP) } \\
\end{array}$ \\
\hline $\begin{array}{c}\text { Turbine Exhaust } \\
\text { Temp, }{ }^{\circ} \mathrm{C}\end{array}$ & $\sim 595$ & $\sim 595$ & & \\
\hline $\begin{array}{c}\text { Turbine } \\
\text { Inlet Pressure, } \\
\text { psig }\end{array}$ & $\sim 265$ & $\sim 300$ & $\sim 450$ & $\begin{array}{l}\sim 1500 \text { (HP) } \\
\sim 625 \text { (IP) }\end{array}$ \\
\hline $\begin{array}{c}\text { Combustor } \\
\text { Exhaust } \\
\text { Composition, \% }\end{array}$ & $\begin{array}{c}\mathrm{CO}_{2}(9.27) \\
\mathrm{H}_{2} \mathrm{O}(8.5) \\
\mathrm{N}_{2}(72.8) \\
\mathrm{Ar}(0.8) \\
\mathrm{O}_{2}(8.6)\end{array}$ & $\begin{array}{c}\mathrm{CO}_{2}(1.4) \\
\mathrm{H}_{2} \mathrm{O}(17.3) \\
\mathrm{N}_{2}(72.2) \\
\mathrm{Ar}(0.9) \\
\mathrm{O}_{2}(8.2)\end{array}$ & $\begin{array}{c}\mathrm{H}_{2} \mathrm{O}(82) \\
\mathrm{CO}_{2}(17) \\
\mathrm{O}_{2}(0.1) \\
\mathrm{N}_{2}(1.1) \\
\mathrm{Ar}(1)\end{array}$ & $\begin{array}{c}\mathrm{H}_{2} \mathrm{O}(75-90) \\
\mathrm{CO}_{2}(25-10) \\
\mathrm{O}_{2}, \mathrm{~N}_{2}, \mathrm{Ar} \\
(1.7)\end{array}$ \\
\hline
\end{tabular}

In addition to increased TITs, the advanced hydrogen-fired and oxy-fuel turbines are projected to operate in a combustion gas environment containing $>20 \%$ moisture (Table 1). Important criteria for structural materials exposed to the combination of high temperature (i.e., above $\sim 1000^{\circ} \mathrm{C} ; \sim 1830^{\circ} \mathrm{F}$ ) and high steam concentrations include sufficient thermal stability, low vapor pressure of the surface materials and/or the reaction product(s) formed, and compatibility of any coating material with the underlying substrate. With regard to this last criterion, surface protection via an oxidation resistant coating is, in reality, a necessity, and it will be critically important to maintain the stability of the coating for an extended service (i.e., 8,000-30,000 hrs). This means that there must be minimal interdiffusion between the substrate and the surface-modified region. The constraint of long-term resistance in steamcontaining environments at very high temperatures removes surface modifications that are or react to form silica- or chromia-based products. A viable engineering solution is to utilize a metallic $\mathrm{Al}_{2} \mathrm{O}_{3}$-scale forming surface coating with an intermediate diffusion barrier that will essentially preclude coating-substrate interdiffusion and, hence, sustain the protective properties of the coating.

As commercially applied diffusion or overlay bond coat systems are subjected to high temperature for extended periods of time, oxidation (i.e., formation of thick TGOs) and rumpling of the bond coat surface result which induce stress and spallation of the insulating air plasma sprayed (APS) or electron beam physical vapor deposition (EB-PVD), yttria stabilized zirconia (YSZ) TBCs - ultimately leading to reduced turbine operating life. Mitigating not only bond coat oxidation, but also surface rumpling are essential for extending the operating lifetime of TBC systems.

Incorporating the use of commercially applied YSZ TBCs extends the operating use of current nickel-based superalloy and single crystal substrates to $\sim 1200-1300^{\circ} \mathrm{C}\left(\sim 2190-2370^{\circ} \mathrm{F}\right)$. Above these temperatures significant sintering leads to microstructural changes and a reduction of the strain tolerance in combination with an increase of Young's modulus. Additionally phase transformations occur, leading to the formation of tetragonal and cubic phases. Upon cooling, the tetragonal phase further undergoes transformation to the monoclinic phase which is accompanied by a volume change, leading to spallation of the coating. To extend turbine airfoil operation to temperatures $>1300^{\circ} \mathrm{C} \quad\left(>2370^{\circ} \mathrm{F}\right)$, extreme temperature coatings as those materials with pyrochlore structures and high melting points (i.e., $\mathrm{La}_{2} \mathrm{Zr}_{2} \mathrm{O}_{7}, \mathrm{La}_{2} \mathrm{Hf}_{2} \mathrm{O}_{7}$, $\mathrm{Gd}_{2} \mathrm{Zr}_{2} \mathrm{O}_{7}$ or $\mathrm{Nd}_{2} \mathrm{Zr}_{2} \mathrm{O}_{7}$ ) are being evaluated.

Traditionally, materials technology for power generation gas turbines has followed the aircraft technology [4]. During the last decade, dramatic competition in the power equipment industry has boosted technology to the level achieved in the aviation turbines just years before [5]. Industrial gas turbines (IGTs) use single crystal and directionally solidified blades and vanes, rhenium-containing nickel-based superalloys, advanced metallic and ceramic coatings. The large size of IGT

This material is declared a work of the U.S. Government and is not subjected to copyright protection in the United States. Approved for public release; Distribution is unlimited. 
components shows limits of traditional casting techniques, and newly developed (gas cooling casting) or rediscovered (liquid metal cooling) processes are being extensively evaluated. Single crystal components require also a new generation of reconditioning technologies, such as epitaxial brazing and laser cladding. Differences in component size and, especially, operating conditions, will result in stronger separation of aero and IGT material development lines in the future.

\section{APPROACH}

In order to maintain the structural integrity of future land-based power generation turbine components under the extreme conditions shown in Table 1, (1) durable TBCs, (2) high temperature creep resistant metal substrates, and (3) effective cooling techniques, will be required. While advances in substrate materials have been limited for the past decades, thermal protection of turbine airfoils for future hydrogen-fired and oxy-fuel turbines will rely primarily on collective advances in TBCs and aerothermal cooling. To address the DOE FE goals for Advanced Power Systems, NETL-RUA has developed an integrated materials, heat transfer, and secondary flow team effort whose primary goal is focused on achieving

- Development of advanced material system architectures that permit operation of turbine airfoils at temperatures $\geq 50-100^{\circ} \mathrm{C}$ higher than current SOTA components.

- Development of novel, manufacturable, internal airfoil cooling technology concepts that achieve a cooling enhancement factor of $\sim 5$.

- Development of advanced, manufacturable, airfoil film cooling concepts that achieve a 50\% reduction in required cooling flow.

- Design, construction and operation of a world-class test secondary flow rig facility for testing new cooling improvement strategies for the turbine rotating blade platform which ultimately reduce fuel burn.

Specific to the area of materials development, efforts at NETL and CFI have been focused on development of a wet spray diffusion bond coat system that can be applied to nickelbased superalloys and single crystal substrates and integrated with either commercially sprayed APS or EB-PVD YSZ TBCs, or with overlay coatings capable of providing thermal insulating properties up to temperatures approaching 1600$1700^{\circ} \mathrm{C}\left(\sim 2910-3090^{\circ} \mathrm{F}\right)$ (Figure 1). Additionally integration of the low cost diffusion bond coat with diffusion barrier coatings (DBCs) developed at the University of Pittsburgh has been undertaken to mitigate interdiffusion of bond coat systems and the underlying metal substrate, in order to retain a protective alumina scale along the external surface of the bond coat, as well as retain alumina within a reservoir along the surface of the metal substrate during extended high temperature operation.

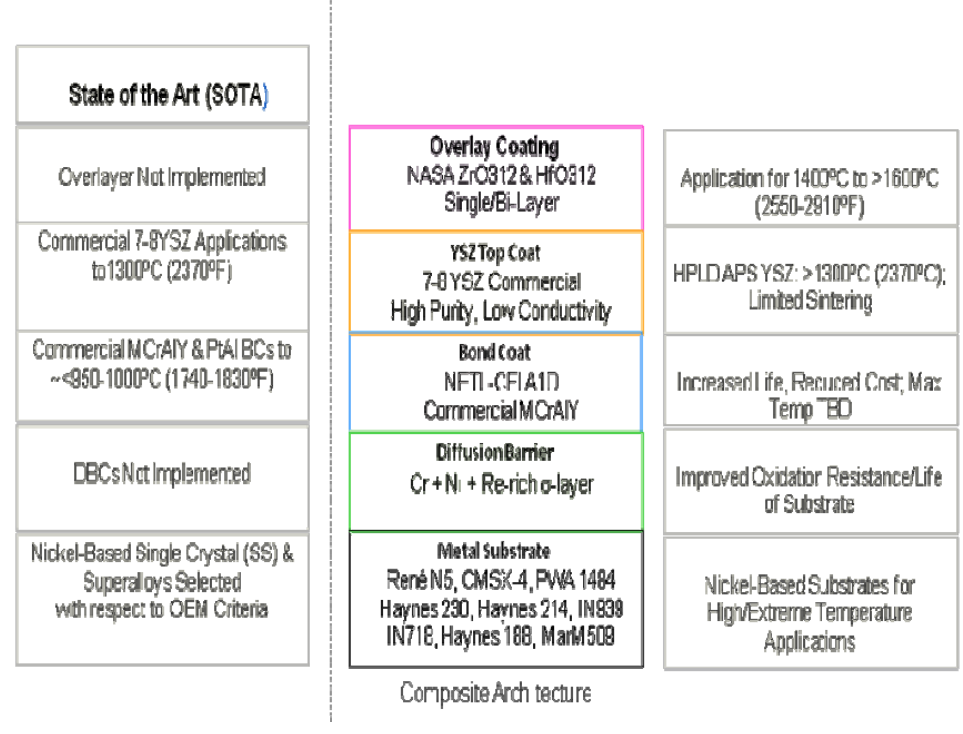

Figure 1 - NETL TBC composite architecture

Determination of the coating's material properties as a function of exposure time in high temperature, air and/or steam-containing environments, simulating either hydrogenfired or oxy-fuel turbine conditions, provides a basis for establishing residual coating durability and life. Utilizing the high temperature micro-indentation techniques developed at West Virginia University provides capabilities for predicting potential TBC spallation locations on metal substrates prior to their occurrence. The efforts and technical accomplishments in each of these materials development areas follow.

\section{MATERIALS DEVELOPMENT}

\section{Bond Coat System Development and Integration with Extreme Temperature Overlays}

Commercial bond coatings that are used in the production of TBCs consist of two types: the MCrAlY overlays $(\mathrm{M}=\mathrm{Ni}, \mathrm{Co})$ and Pt-aluminide diffusion coatings. Overlay coatings are applied by low pressure plasma spray (LPPS), high velocity oxygen fuel (HVOF), or air plasma spray (APS) thermal spray processes. Diffusion aluminides are manufactured by pack cementation, above the pack techniques, chemical vapor deposition (CVD), or slurry processes. In order to demonstrate the feasibility for development of a reduced cost, high temperature, oxidation resistant bond coat, NETL has collaboratively worked with CFI to develop bond coat systems targeted for use in advanced hydrogen-fired and oxy-fuel landbased turbine applications. The bond coats consist primarily of aluminum particles suspended in a binder system that is sprayed onto the surface of single crystal (i.e., René N5) coupons. The coupons are subsequently diffused at temperatures approaching $1070^{\circ} \mathrm{C}\left(\sim 1960^{\circ} \mathrm{F}\right)$ resulting in the formation of a dense surface layer containing primarily $\beta$ nickel aluminide (Figure 2). Chromium, cobalt and small

This material is declared a work of the U.S. Government and is not subjected to copyright protection in the United States. Approved for public release; Distribution is unlimited. 
amounts of finely dispersed refractory metals (i.e., Ta, W, Mo, and $\mathrm{Re}$ ) from the underlying metal substrate are present in the coating indicating that the high activity bond coat, referred to as A1D, had been inwardly grown. The thicknesses of the bond coat and interdiffusion zone consistently have been identified as $\sim 50-55 \mu \mathrm{m}$ and $\sim 25-30 \mu \mathrm{m}$, respectively.

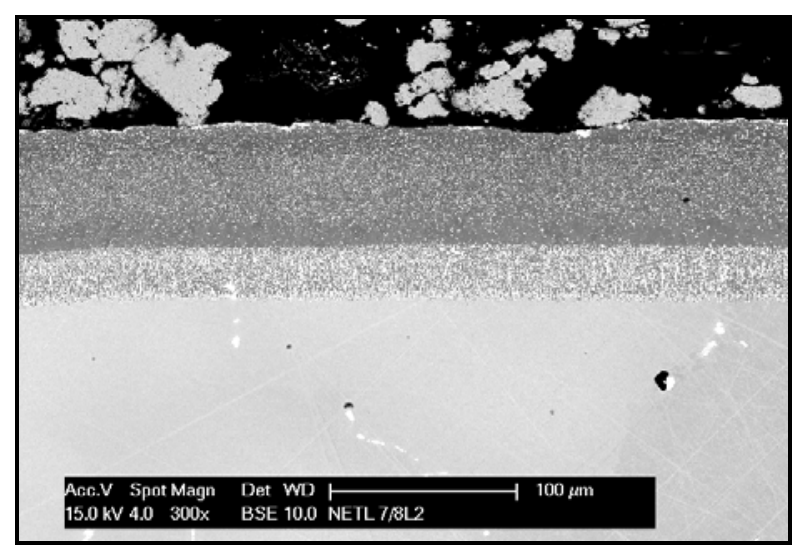

Figure 2 - Cross-sectional micrograph of the A1D bond coat system

In order to address the high temperature oxidative stability of these systems, René N5/A1D coupons were subjected to extended cyclic bottom-loading furnace testing at $1100^{\circ} \mathrm{C}$ $\left(\sim 2010^{\circ} \mathrm{F}\right)$. The mass change of the coupons was monitored as a function of time, and post-test cross-sectional scanning electron microscopy (SEM) analyses were performed. These data were compared to results obtained for similarly tested commercial SOTA MCrAlY $(\mathrm{M}=\mathrm{NiCo})$ and Pt-Al bond coat systems, as well as uncoated René N5/Y. Bench-scale testing indicated that with the addition of the A1D coating along the external surface of René N5/Y, the cyclic oxidation stability of the single crystal substrate was approximately tripled (René N5/Y: 850 cycles vs René N5/A1D: 2,120 cycles prior to crossing through zero mass change). The René N5/A1D system was shown to exceed the $1100^{\circ} \mathrm{C}\left(\sim 2010^{\circ} \mathrm{F}\right)$ cyclic oxidation life of René N5/SOTO-PtAl and René N5/Pt-Hf Mod $\gamma-\gamma$ ' G2P $(\sim 1,600$ and $\sim 1,100$ thermal cycles, respectively; Figure 3).

Post-test cross-sectional SEM analyses indicated that the external surface of the A1D bond coat was relatively planar after 2,100 thermal cycles, which implies that enhanced adherence of applied YSZ TBC layers would occur, as ratcheting or rumpling of the bond coat surface is negligible. Internal detrimental secondary reaction zones (SRZ) were not observed after extended high temperature exposure of the A1D bond coat system.

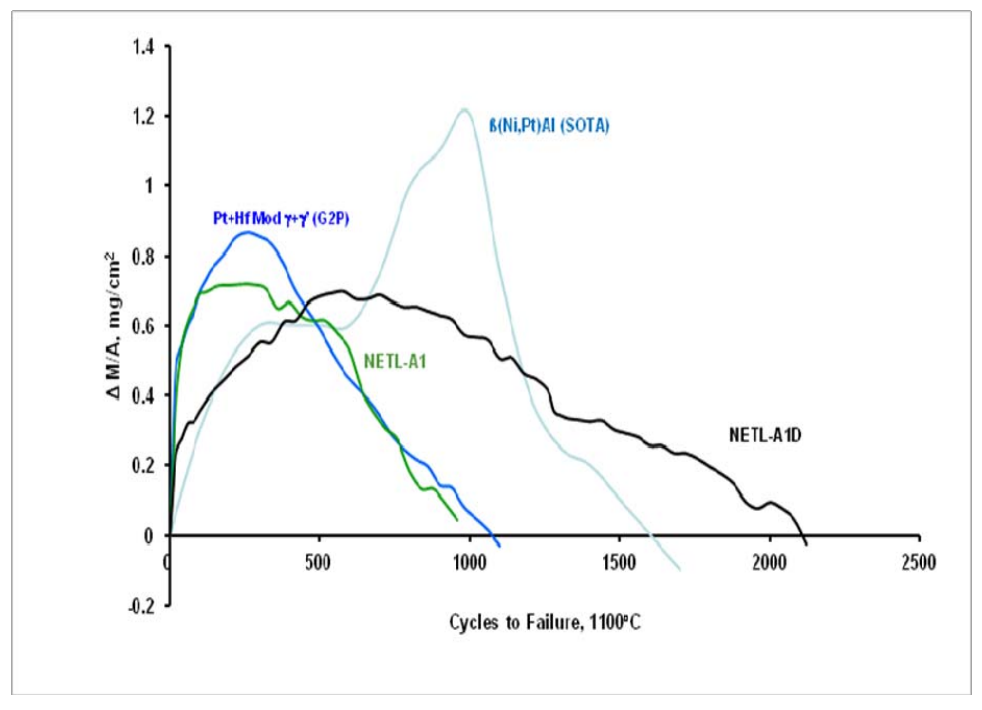

Figure 3 - Mass change as a function of cyclic oxidation at $1100^{\circ} \mathrm{C}\left(\sim 2010^{\circ} \mathrm{F}\right)$ for diffusion-based bond coat systems
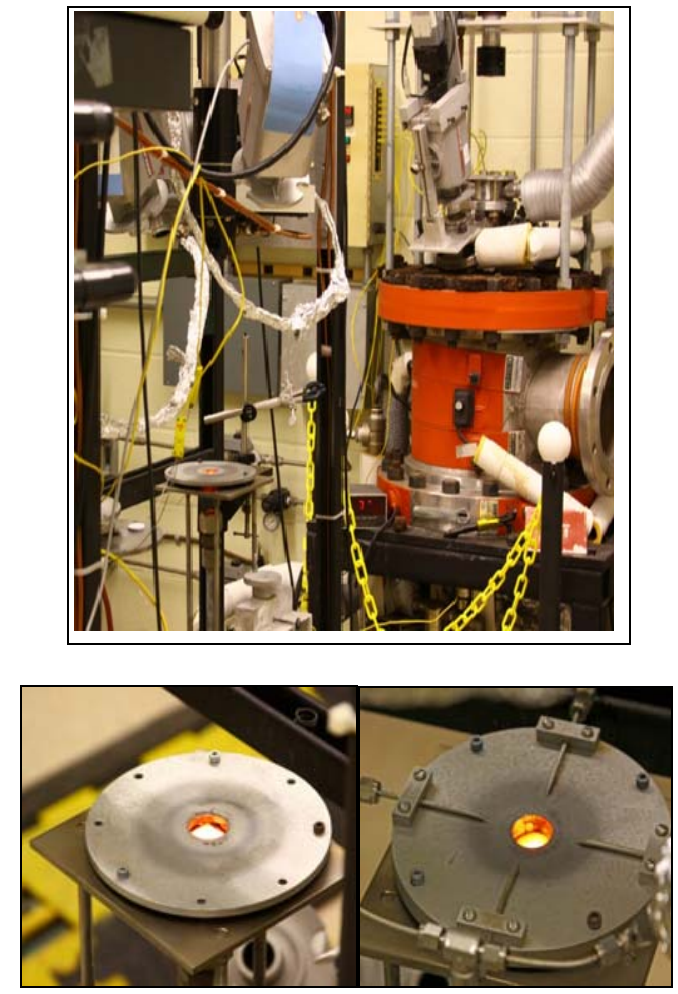

Figure 4 - NASA GRC laser flux test facility

Bottom left photo: Coupon exposure in air at $\sim 1100^{\circ} \mathrm{C}\left(\sim 2010^{\circ} \mathrm{F}\right)$ Bottom right photo: Coupon exposure in air/steam at $\sim 1100^{\circ} \mathrm{C}\left(\sim 2010^{\circ} \mathrm{F}\right)$

As these materials are projected to experience high steam concentrations (Table 1), and thermal gradients through the thickness of the ceramic-metal architecture as the result of internal cooling that will be required to maintain metal substrate temperatures at $<1100^{\circ} \mathrm{C}\left(<2010^{\circ} \mathrm{F}\right)$, further testing

This material is declared a work of the U.S. Government and is not subjected to copyright protection in the United States. Approved for public release; Distribution is unlimited. 
was conducted in NASA GRC's air and steam thermal flux test facilities (Figure 4). Five tests were conducted during FY11 which maintained the bond coat surface temperature at $\sim 1100^{\circ} \mathrm{C}\left(\sim 2010^{\circ} \mathrm{F}\right)$ for 1 hour followed by 3 minutes at room temperature, with repeated cycling for a total of 50 hours of testing. With time, the surface temperature of the bond coat increased slightly due to increased laser power absorption from the oxide scale which formed. During testing, slight laser power adjustments were made in order to maintain a constant bond coat surface temperature. After 50 hours of laser flux testing in either air or steam, the surfaces of the René N5/A1D coupons visually appeared to be intact (i.e., absence of material removal or spallation).

Post-test cross-sectional SEM analyses of the René N5/A1D coupons indicated that although cracks were intermittently evident in the bond coat after laser thermal flux exposure, little if any evidence of coating failure had occurred, as there was no indication of aluminum depletion in the coating. The average thickness of the surface oxide that formed after 50 hours of exposure in air was $\sim 18 \mu \mathrm{m}$, while in steam an average $\sim 19.6 \mu \mathrm{m}$ scale thickness was formed. Surface energy dispersive $\mathrm{X}$-ray analyses (EDAX) identified the presence of alumina with hafnium-rich transient oxides.

Thermal flux testing was additionally conducted in air and in steam using René N5/A1D coupons that were coated with $\sim 250-270 \mu \mathrm{m}$ commercial 7-8 APS YSZ and $~ 550 \mu \mathrm{m}$ NASA GRC's low conductivity $\mathrm{ZrO} 312$ coating $\left(\mathrm{ZrO}_{2}-2.8 \mathrm{wt} \% \mathrm{Y}_{2} \mathrm{O}_{3}\right.$ $3.3 w t \% \mathrm{Gd}_{2} \mathrm{O}_{3}-3.6 \mathrm{wt} \% \mathrm{Yb}_{2} \mathrm{O}_{3}$; Figure 5). A René N5/LPPS MCrAlY/APS YSZ/ZrO312 coupon $(\sim 300 \mu \mathrm{m}$ MCrAlY) was additionally subjected to laser flux testing. The external surface temperature of each coupon was maintained at $\sim 1480^{\circ} \mathrm{C}\left(\sim 2700^{\circ} \mathrm{F}\right)$, with an interface bond coat temperature of $\sim 1100^{\circ} \mathrm{C}\left(\sim 2010^{\circ} \mathrm{F}\right)$, and a back surface metal substrate temperature of $\sim 1000^{\circ} \mathrm{C}\left(\sim 1830^{\circ} \mathrm{F}\right)$. During the first hours of exposure at temperature which were followed by cooling to room temperature, the thermal conductivity of the TBC coating increased possibly due to sintering and/or porosity reduction within the topcoat layers. Thereafter very slight conductivity reduction resulted possibly from defect formation (i.e., gaps; microcracks) within the topcoat or along the TGO interface. At test termination after being subjected to 50 hours of thermal flux testing in air, the TBC coatings visually appeared to be intact (Figure 6). Very minor edge buckling or spallation was observed for the MCrAlY coupon. In contrast, after 49 cycles in steam, the René N5/A1D/APS YSZ/ZrO312 coupon experienced spallation along half of the coated coupon surface, possibly as the result of exposure to the steam thermal flux environment or from stresses imposed along the edge of the coupon by test fixture clamping.

Post-test microstructural characterization indicted that when the coupons were subjected to thermal flux testing in air, there was little evidence of coating failure. Specifically, although there were features of aluminum depletion in both the A1D and MCrAlY bond coats, both maintained a continuous alumina TGO surface scale $(\sim 5 \mu \mathrm{m}$, and $\sim 5-10 \mu \mathrm{m}$, respectively). SEM characterization, however, indicated that the MCrAlY overlay bond coat had more extensive degradation than the A1D diffusion bond coat, that is, the overlay coating had numerous large internal oxide formations (Figure 7), while the diffusion coating did not. The superior performance of the diffusion coating is considered to be due, at least in part, to a higher aluminum concentration in the silicon-containing $\beta$-A1D aluminide coating in comparison to the lower aluminum-containing $\gamma+\beta$ MCrAlY coating.

Surface SEM characterization of the air exposed coupons indicated that some flaking of the porous $\mathrm{ZrO} 312$ coating had occurred which is characteristic of plasma sprayed ceramic coatings after thermal cycling.

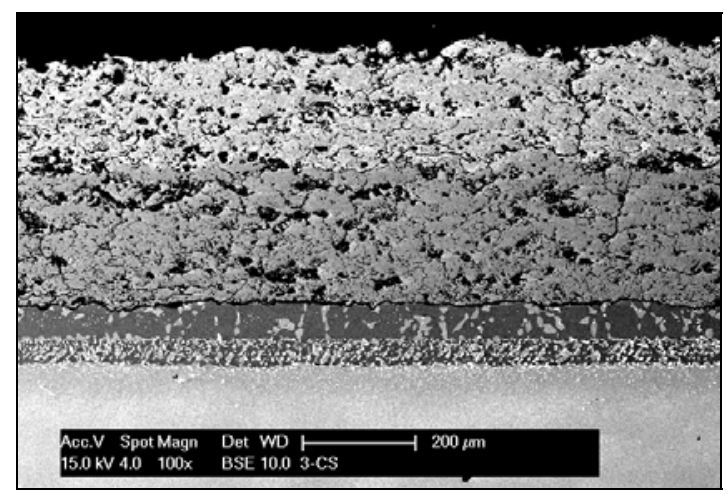

Figure 5 - Cross-sectional micrograph of the René N5/A1D/YSZ/ZrO312 coupon after $50 \mathrm{hrs}$ of thermal flux testing in air at $1100^{\circ} \mathrm{C}\left(\sim 2010^{\circ} \mathrm{F}\right)$

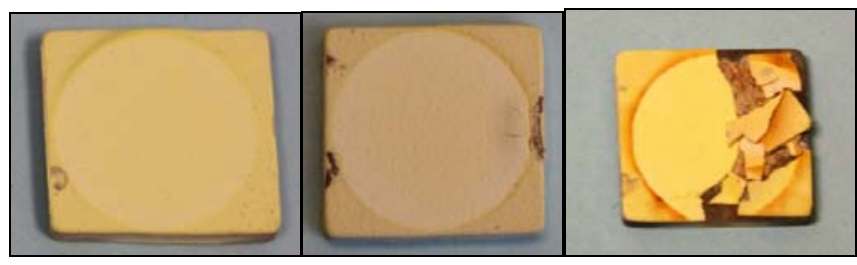

Figure 6 - TBC Coated Coupons after Laser Flux Testing Left photo: René N5/A1D/APS YSZ/ ZrO312; Air at $\sim 1482^{\circ} \mathrm{C}\left(2700^{\circ} \mathrm{F}\right)$, $50,1 \mathrm{hr}$ cycles

Middle photo: René N5/LPPS MCrAlY/APS YSZ/ZrO312; Air at $\sim 1482^{\circ} \mathrm{C}$ $\left(2700^{\circ} \mathrm{F}\right), 50,1 \mathrm{hr}$ cycles

Right photo: René N5/A1D/APS YSZ/ZrO312; Steam at $\sim 1482^{\circ} \mathrm{C}\left(2700^{\circ} \mathrm{F}\right)$, $49,1 \mathrm{hr}$ cycles

This material is declared a work of the U.S. Government and is not subjected to copyright protection in the United States. Approved for public release; Distribution is unlimited. 


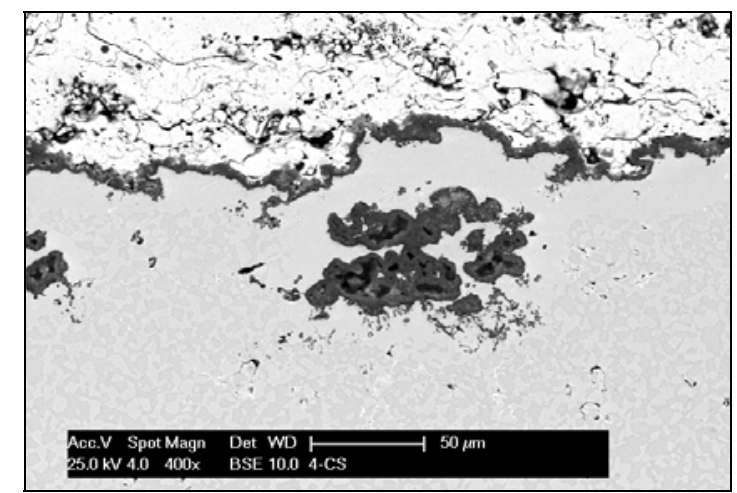

Figure 7 - SEM cross-sectional micrograph illustrating internal oxidation of the bond coating of the René N5/LPPS MCrAlY/APS/ZrO312 coupon

When exposed to steam, failure of the René N5/A1D/APS $\mathrm{YSZ} / \mathrm{ZrO} 312$ coating occurred as a result of cracking in the TBC adjacent to the ceramic bond coat interface. Investigators in numerous prior studies of plasma sprayed ceramic coatings suggest that this type of failure is the result of thermal mismatch between the bond coat and the TBC. However, if thermal expansion mismatch alone were the cause of the observed failure, then for a given set of cyclic test parameters, all three coupons should have failed, but they did not. Published information on oxidation in air plus water vapor indicates that water vapor increases the growth rate of alumina at high temperature. Post-test characterization of the René N5/A1D coupons identified the formation of a continuous $\sim 2 \mu \mathrm{m}$ and $\sim 2.5 \mu \mathrm{m}$ alumina scale after 50 hours of exposure at $1100^{\circ} \mathrm{C}\left(\sim 2010^{\circ} \mathrm{F}\right)$ in air and steam, respectively. When coated with an external TBC layer, an $\sim<5$ $\mu \mathrm{m}$ and $\sim 3-7 \mu \mathrm{m}$ scale formed along the A1D surface of the René N5/A1D/APS YSZ/ZrO312 coupons after 50 hours of exposure in air and steam, respectively. The slight increase in TGO thickness for coupons with an APS YSZ coating reflects additional exposure time at high temperature during application of the TBC, as well as possible diffusion of oxygen from the YSZ at the bond coat interface. In contrast an $\sim 5-10 \mu \mathrm{m}$ scale formed along the surface of the René N5/ LPPS MCrAlY/ZrO312 coupon after 50 hours of laser flux testing in air. If it were suggested that the internal stress in the TBC increases as alumina forms, then coupons with a faster growing oxide would have greater internal stress after the same thermal exposure time, than coupons with a slower growing scale on the bond coat. If this were the case, then the René N5/LPPS MCrAlY/APS/ZrO312 coating should similarly have failed. A combination of internal stress, and possibly stress resulting from test fixture clamping are considered as contributors to failure of the René N5/A1D/APS $\mathrm{YSZ} / \mathrm{ZrO} 312$ coating during high temperature, thermal flux, steam exposure.

\section{Diffusion Barrier Coating Systems}

Important criteria for structural materials exposed to the combination of high temperature (i.e., above $\sim 1000^{\circ} \mathrm{C}$; $\sim 1830^{\circ} \mathrm{F}$ ) and high steam concentrations include sufficient thermal stability, low vapor pressure of the surface materials and/or the reaction product(s) formed, and compatibility of any coating material with the underlying substrate. As a result, surface protection via an oxidation resistant coating is essential for extended high temperature exposure (i.e., 8,000-30,000 hrs of turbine operating life), with minimal interdiffusion between the substrate and the surface-modified region. The constraint of long-term resistance in steam-containing environments at very high temperatures removes surface modifications that are or react to form silica- or chromia-based products. A viable engineering solution is to utilize a metallic $\mathrm{Al}_{2} \mathrm{O}_{3}$-scale forming surface coating with an intermediate diffusion barrier that will essentially preclude coating-substrate interdiffusion and, hence, sustain the protective properties of the coating.

Recent research on rhenium-base alloys has shown a range of Re-Cr-Ni-based compositions can act as a highly effective diffusion barrier layer between a heat resistant alloy and an Alreservoir layer to form and maintain a protective, long lasting $\mathrm{Al}_{2} \mathrm{O}_{3}$ scale [6]. Coatings with a two-layer structure comprised of an inner, Re-base alloy layer and an outer $\beta$-NiAl layer have been successfully formed on the nickel-base superalloys and even niobium-base alloys.

With respect to NETL-RUA's DBC development during FY11, DBC-source powder was prepared at the Ames Laboratory via high-energy mechanical milling (Zoz mill). The $\sigma$-DBCs were deposited at the Caterpiller Inc.'s Technical Center via HVOF deposition onto nickel-based Haynes 230 and Haynes 214 substrates which were provided by Haynes International. The Al-reservoir layer was a standard NiCrAl overlay (Ni-343 from Praxair) that was also deposited via HVOF. The advantage of directly depositing the DBC systems by a plasma spray process is that it provides practical tractability and compositional flexibility. The nominal composition of the NiCrAlY overlay coating was $67 \mathrm{Ni}-22 \mathrm{Cr}-10 \mathrm{Al}-1 \mathrm{Y}(\mathrm{wt} \%)$.

DBC layers that were formed during conduct of this effort had thicknesses of $\sim 20 \mu \mathrm{m}$ and $45 \mu \mathrm{m}$ (referred to as "thin" and "thick" respectively; Figure 8). For the DBCs, the targeted composition was $40 \mathrm{Re}-40 \mathrm{Cr}-20 \mathrm{Ni}$ (at $\%$ ); however, EDAX analysis revealed that the average composition of the thick DBC was 50Re-24Cr-26Ni (at $\%)$; while that of the thin DBC was $72 \mathrm{Re}-14 \mathrm{Cr}-11 \mathrm{Ni}$. The reason(s) for the thin DBC composition being quite different from the targeted composition is currently not understood, but it is noteworthy that such a Re-rich composition corresponds to an (unwanted) equilibrium $\sigma+\delta$-Re $+\gamma$-Ni phase constitution.

The general performance of the deposited DBC systems was assessed by conducting thermal exposures at $1100^{\circ} \mathrm{C}$ and

This material is declared a work of the U.S. Government and is not subjected to copyright protection in the United States. Approved for public release; Distribution is unlimited. 
$1200^{\circ} \mathrm{C}\left(\sim 2010^{\circ} \mathrm{F}\right.$ and $\left.\sim 2190^{\circ} \mathrm{F}\right)$. Of particular interest were the stability and effectiveness (in terms of serving as a diffusion barrier) of the DBCs tested.
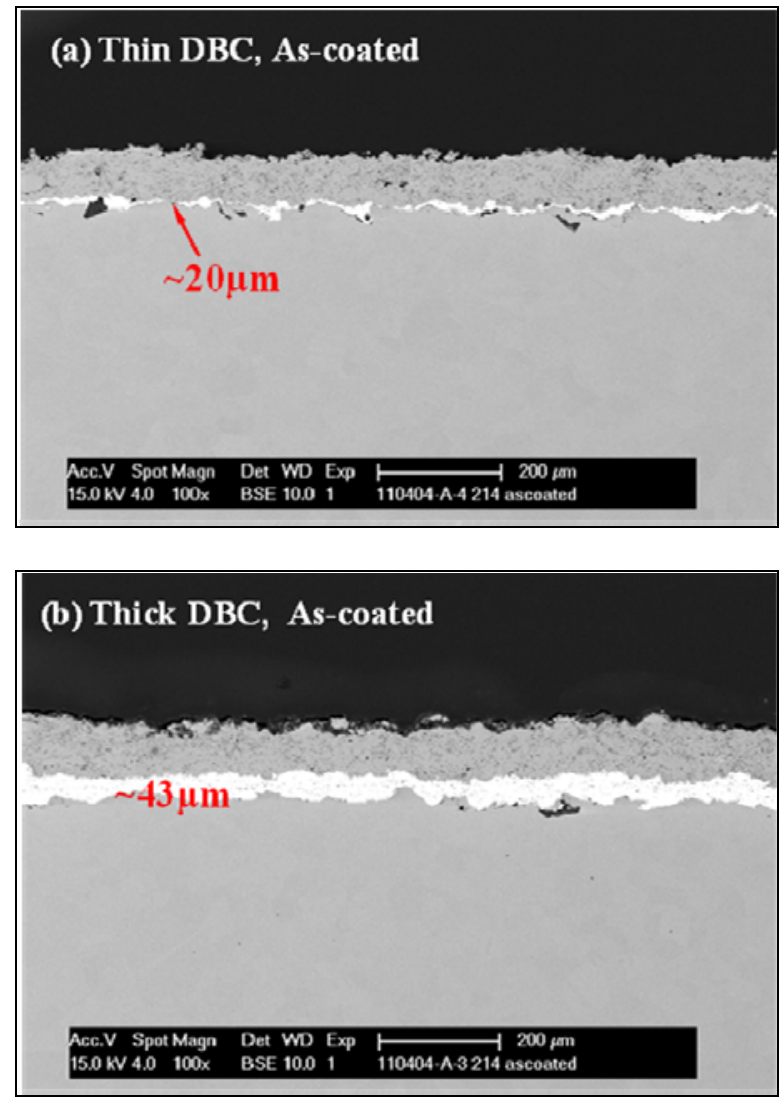

Figure 8 - Representative cross-sectional micrographs of the as-manufactured (a) thin and (b) thick DBC systems

For the thick DBC deposited on Haynes 214, there was found to be little change in Re content after $100 \mathrm{hrs}$ of thermal exposure at $1100^{\circ} \mathrm{C}\left(\sim 2010^{\circ} \mathrm{F}\right)$; although, a small amount of a Cr-enriched phase formed at the NiCrAlY/DBC interface (Figure 9). For thin DBCs, some degree of incompatibility between the $\mathrm{DBC}$ and the NiCrAlY overlay was evident. Even so, the DBC was effective.

The thick DBC was also found to be reasonably effective for exposures at $1200^{\circ} \mathrm{C}\left(\sim 2190^{\circ} \mathrm{F}\right)$; although, $\operatorname{Re}$ was found to have diffused from the $\mathrm{DBC}$ to the NiCrAlY coating and $\mathrm{Al}$ from the coating to the $\mathrm{DBC}$, as well as permeability of constituents from the DBC into the Haynes 214 substrate. As a consequence, there was a measureable change in the $\mathrm{DBC}$ composition with increasing exposure time at $1200^{\circ} \mathrm{C}$ $\left(\sim 2190^{\circ} \mathrm{F}\right)$. For both the thin and the thick DBC systems, there was no evidence of interactions that led to the formation of embrittling topologically closed packed (TPC) phases.
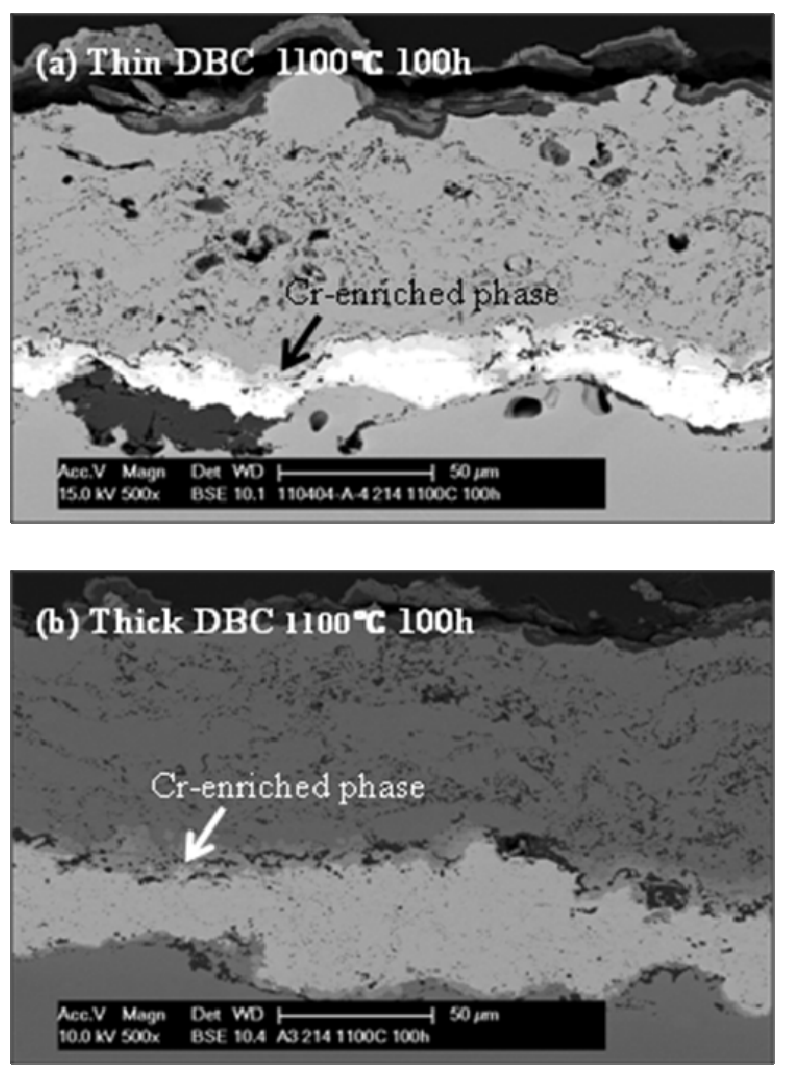

Figure 9 - Cross-sectional micrographs of the (a) thin and (b) thick DBC systems after $100 \mathrm{hrs}$ exposure at $1100^{\circ} \mathrm{C}$ $\left(\sim 2010^{\circ} \mathrm{F}\right)$

\section{Micro-Indentation Stiffness Evaluation of Thermal Barrier Coated Materials}

To address extended TBC stability and potential life, unique bench-scale, micro-indentation, non-destructive test facilities were constructed at West Virginia University. Durability testing at room temperature was conducted during FY10 on commercially TBC coated René N5 coupons that were subjected to extended high temperature exposure and subsequent micro-indentation characterization to address residual stiffness of the coating, as well as to project potential coating spallation. Similarly during FY10, the residual stresses generated within the $\mathrm{TBC} /$ bond coat interface due to thermal cyclic loadings were correlated to measured indentation stiffness response of TBCs for predicting coating life (i.e., spallation failure) [7-17]. The unloading surface stiffness responses obtained from micro-indentation of TBC coupons subjected to various thermal loadings has proven to be a viable criterion for predicting TBC spallation failure location. Based on a multiple loading/partial unloading procedure, slopes from various loads were able to be evaluated for abnormalities or correlation to thermal loading cycles. Failure locations for both isothermal and cyclically exposed René N5/MCrAlY/APS, as well as René N5/MDL/EB-PVD TBC coupons were correctly predicted. Finite element analysis of $\mathrm{YSZ} / \mathrm{TGO} /$ bond coat

This material is declared a work of the U.S. Government and is not subjected to copyright protection in the United States. Approved for public release; Distribution is unlimited. 
interface stresses produced upon cooling has provided an explanation to experimentally observed cracking and failure patterns near and within the debonded/spalled region.

During FY11 research efforts at WVU in collaboration with NETL were focused on the design and construction of the high temperature micro-indentation testing system. Figure 10 shows a schematic and the assembled test facility for high temperature micro-indentation testing of coated coupons in a steam-containing environment.
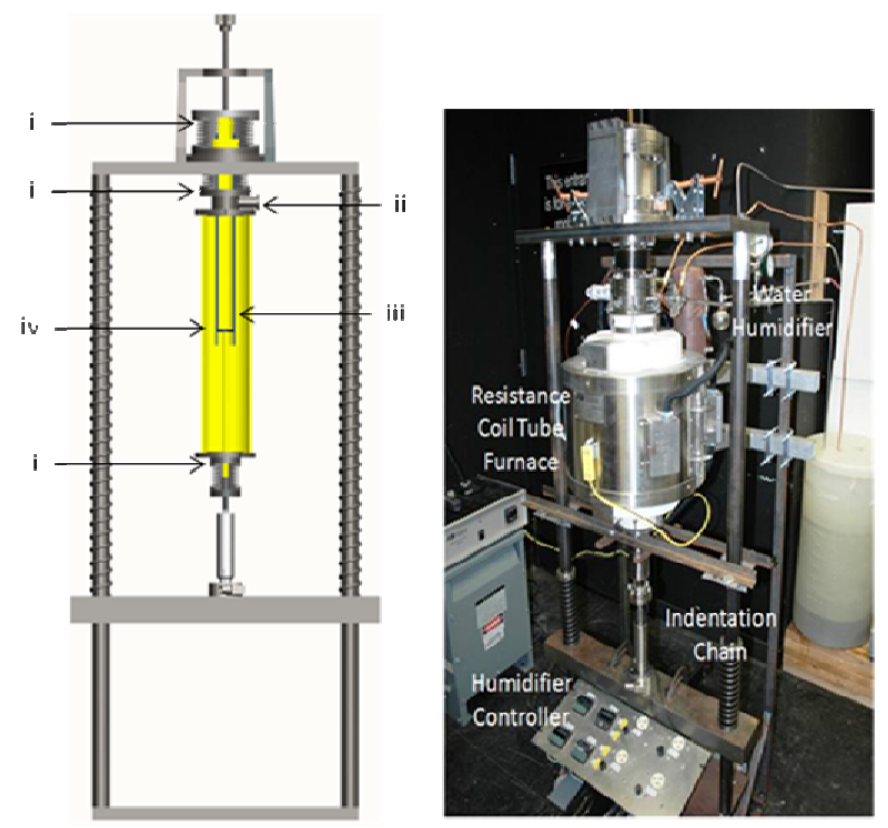

i) stainless steel bellows, ii) as/moisture/vacuum port, iii) sample and iv) cylindrical alumina tube

Figure 10 - High temperature micro-indentation system

For calibration purposes, commercially as-manufactured René N5/MCrAlY/APS YSZ TBC coupons were first subjected to surface stiffness measurements using a room temperature, table-top, micro-indentation test unit. The coupon was then mounted in the high temperature micro-indentation test facility, and after proper loading alignment, in-situ room-temperature micro-indentation tests were performed. The resulting coating surface stiffness values were shown to be comparable for testing in either micro-indentation test facility (i.e., $21.8 \mathrm{GPa}$ and $19.2 \mathrm{GPa}$, respectively). The as-manufactured TBC surface response data serve as the initial or baseline René N5/MCrAlY/APS YSZ TBC stiffness which would be used for comparison during extended high temperature exposure.

In-situ micro-indentation testing was then conducted on a René N5/MCrAlY/APS coupon after $\sim 100$ hrs of exposure to temperatures of $1100^{\circ} \mathrm{C}\left(\sim 2010^{\circ} \mathrm{F}\right)$. In-situ indentation testing was additionally conducted on a second as-manufactured René N5/MCrAlY/APS coupon that was subjected to thermal cyclic loading conditions. This consisted of heating the TBC coupon to $1100^{\circ} \mathrm{C}\left(\sim 2010^{\circ} \mathrm{F}\right)$ with in-situ indentation testing, and then cooling the coupon to room temperature with in-situ indentation testing. This procedure was subsequently repeated during extended high temperature exposure in air.

Due to the nature of in-situ high-temperature micro-indentation testing, substantial data noise occurred which is unavoidable. A data selection approach was adopted where only the linear portion of the unloading data is used for the surface stiffness response measurement (i.e., data shown in red; Figure 11).

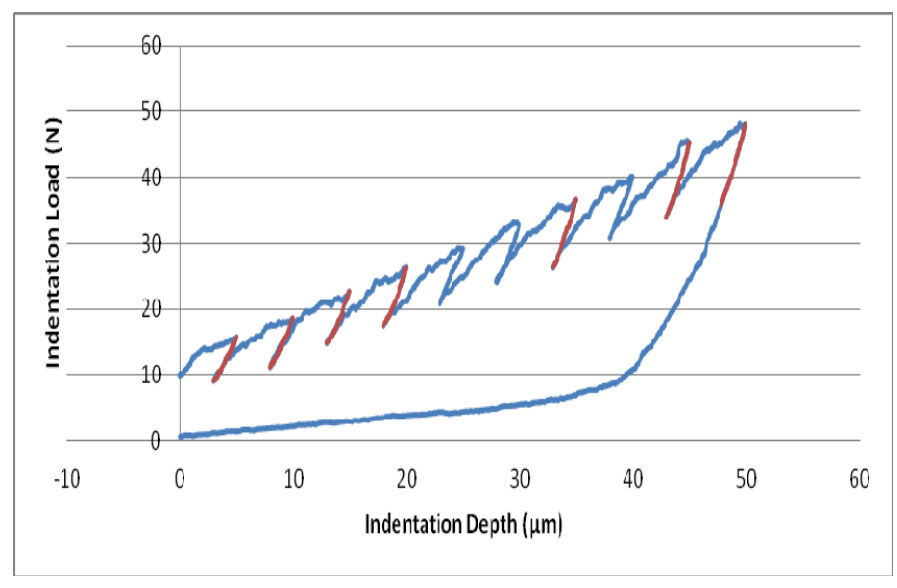

Figure 11 - In-situ micro-indentation testing of René N5/MCrAlY/APS at $1100^{\circ} \mathrm{C}\left(\sim 2010^{\circ} \mathrm{F}\right.$; Cycle 9 , Test 9-1; Measured surface stiffness response: $13.9 \mathrm{GPa})$

As shown in Figures 12 and 13, during the initial hours of testing there was a substantial increase in the measured surface stiffness response at both room temperature and $1100^{\circ} \mathrm{C}$ $\left(\sim 2010^{\circ} \mathrm{F}\right)$. It was expected that some degree of TBC sintering occurred during initial exposure of the as-manufactured 7$8 \mathrm{YSZ}$ coupons to temperatures of $1100^{\circ} \mathrm{C}\left(\sim 2010^{\circ} \mathrm{F}\right)$ (i.e., conditioning of the as-manufactured matrix), leading to an increase in strength. Noticeably there was a substantial increase of measured surface stiffness at room temperature, which can be attributed to residual stress build-up in the TBC (when cooling to room temperature). However, after 40 to 50 hours of high temperature exposure, the measured surface stiffness responses began to decrease. The reduction in surface stiffness was attributed to strength degradation of the 7-8YSZ as micro-cracking results, thus resulting in a loss of strength, during continued thermal cycling.

Figure 14 shows a cross-sectional micrograph of René N5/MCrAlY/APS TBC coupon after being subjected to $\sim 40$ hours of thermal cycling (room temperature to $1100^{\circ} \mathrm{C}$

This material is declared a work of the U.S. Government and is not subjected to copyright protection in the United States. Approved for public release; Distribution is unlimited. 
$\left.\left(\sim 2010^{\circ} \mathrm{F}\right)\right)$. A thin TGO layer was present. Debonding or spallation at the YSZ/TGO or bond coat interface was not observed. As the René N5/MCrAlY/APS TBC coupon is continued to be thermally cycled, the thickness of the TGO layer is projected to increase and alter the interfacial residual stress distribution, leading to eventual interfacial top coat/TGO spallation failure.

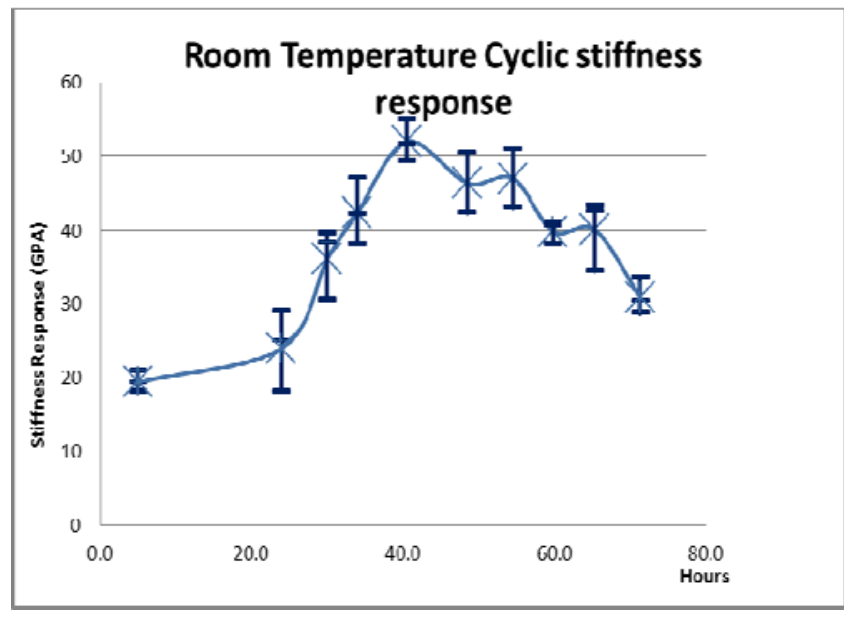

Figure 12 - Surface stiffness response of the René N5/MCrAlY/APS TBC coupon at room temperature

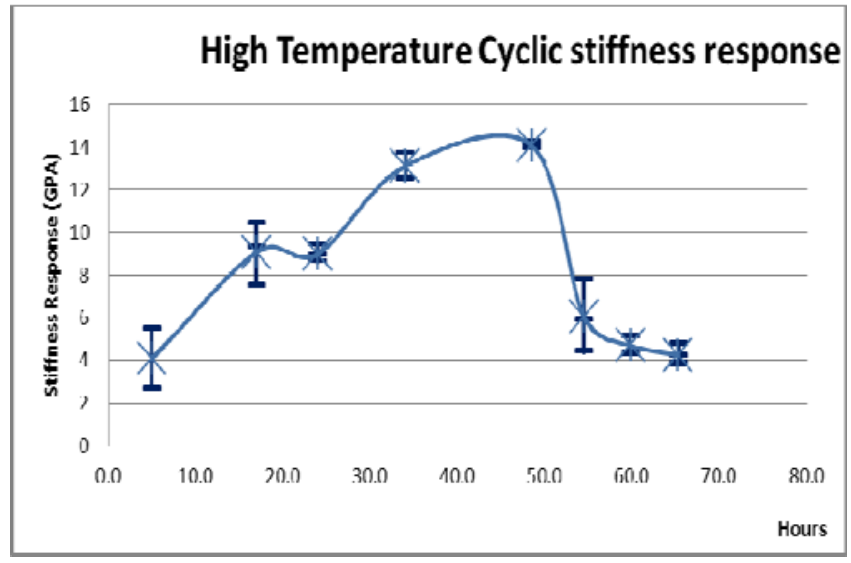

Figure 13 - Surface stiffness response of the René $\mathrm{N} 5 / \mathrm{MCrAlY} / \mathrm{APS}$ TBC coupon at $1100^{\circ} \mathrm{C}\left(\sim 2010^{\circ} \mathrm{F}\right)$

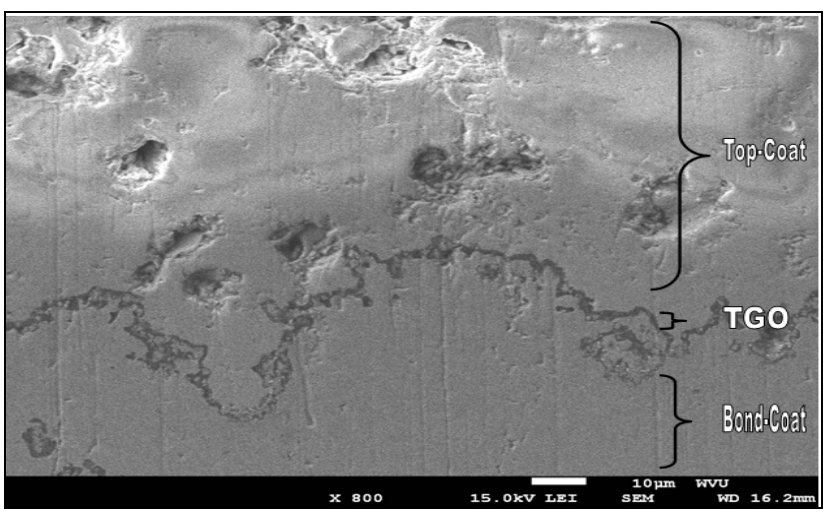

Figure 14 - Cross-section micrograph of the

René N5/MCrAlY/APS coupon after $\sim 40$ thermal cycles (room temperature to $1100^{\circ} \mathrm{C}\left(\sim 2010^{\circ} \mathrm{F}\right)$ )

\section{AEROTHERMAL HEAT TRANSFER ENHANCEMENT AND SECONDARY FLOW REDUCTION}

In addition to the materials and coatings development efforts conducted during FY11, NETL, the University of Pittsburgh, and Virginia Polytechnic Institute and State University (VT), collaboratively demonstrated increased airfoil internal double wall or skin cooling enhancement through the use of novel pinfin arrays achieving heat transfer improvements of a factor of 4.8 over smooth channel architectures for a wide range of Reynolds numbers, as well as a $60-70 \%$ enhancement in cooling effectiveness with a $50 \%$ reduction in coolant mass flow through the use of tripod cooling holes. A collaborative research project was also initiated with The Pennsylvania State University (PSU) that is focused on designing and constructing a world-class test facility for testing new cooling improvement strategies for the turbine rotating blade platform. The primary focus of the turbine test facility is to increase turbine efficiencies by using new designs in sealing the interfaces between stationary and rotating airfoil components. The efforts and technical accomplishments in these areas are presented in detail in alternate publications and conference proceedings [1821].

\section{SUMMARY AND CONCLUSIONS}

With high temperature, high pressure turbine blade operating life greatly exceeding 1,000 hours, and with the $\beta$-phase of the bond coat still remaining, it can be inferred from a knowledge of interdiffusion behaviors that the average metal substrate temperature for current systems is significantly below $1150^{\circ} \mathrm{C}$ $\left(\sim 2100^{\circ} \mathrm{F}\right)$. In current engines, maintaining the stability of the metal substrate requires the application of TBCs and the implementation of effective cooling techniques. The stability of these architectures is, however, limited to temperatures of $<1300^{\circ} \mathrm{C} \quad\left(<2370^{\circ} \mathrm{F}\right)$. Significant advancements in $\mathrm{TBC}$ performance and durability, as well as turbine cooling effectiveness are therefore needed as future engines are designed to be operated at TITs approaching $\sim 1425-1760^{\circ} \mathrm{C}$

This material is declared a work of the U.S. Government and is not subjected to copyright protection in the United States.

Approved for public release; Distribution is unlimited. 
$\left(\sim 2600-3200^{\circ} \mathrm{F}\right)$. As a result, efforts have been focused in the NETL-RUA projects to address potential novel advanced material and airfoil heat transfer concept development for next generation, high temperature, land-based engines.

\section{Bond Coat System Development and Integration with Extreme Temperature Overlays}

In our current materials development research effort, crosssectional examination of the wet sprayed, reduced cost, A1D bond coat indicated that the outer layer was predominantly aluminum-enriched (brittle) NiAl. Although the A1D coating continued to form a protective alumina surface layer during extended thermal cycling, the A1D bond coating was apparently sensitive to cracking when its surface was directly subjected to laser heating. When an APS TBC layer was applied along the A1D bond coat surface, crack formations were not observed after laser flux testing. It should also be noted, the laser flux testing is not commonly used in high temperature cyclic oxidation studies, and consequently, there is little if any data available in the technical literature for comparison purposes.

In order to address the potential for extended operation of TBCs systems at temperatures $>1300^{\circ} \mathrm{C}\left(>2370^{\circ} \mathrm{F}\right)$, René N5 coupons were coated with bond coat systems, as well as with commercially applied YSZ, and NASA GRC's extreme temperature overlay coating. Fifty hours of laser flux testing was completed, exposing the bi-layer $\mathrm{TBC}$ architecture to external coating surface temperature of $\sim 1480^{\circ} \mathrm{C}\left(\sim 2700^{\circ} \mathrm{F}\right)$. The influence of water vapor in the high temperature gas phase environment was shown to impact stability and life of the bilayer coatings during thermal flux testing. Specifically, coupons tested in steam failed while those tested in air did not.

For coupons tested in air, the MCrAlY overlay bond coat was more severely degraded than the A1D diffusion aluminide, which may be a direct result of the lower aluminum concentration in the MCrAlY overlay coating compared to the silicon-containing aluminide. Consequently, the TBC system with the A1D diffusion aluminide bond coat would probably endure more thermal cycles (i.e., longer high temperature life) prior to failure than that with an MCrAlY bond coating.

\section{Diffusion Barrier Coating Systems}

In order to demonstrate proof-of-concept of deposition and functionality of the DBC system on a nickel-based substrate, Haynes 230 and Haynes 214 were selected for the initial DBC materials development effort. Results for tests using Haynes 230 and Haynes 214 substrates suggest that an HVOFdeposited $\mathrm{DBC}$ can be effective for a NiCrAlY bond coat overlay, but effectiveness decreases with increasing exposure temperature above $1100^{\circ} \mathrm{C}\left(\sim 2010^{\circ} \mathrm{F}\right)$.

At $1100^{\circ} \mathrm{C}\left(\sim 2010^{\circ} \mathrm{F}\right)$, when primarily of $\sigma$-composition, the DBC was adequately stable, showing no obvious decrease in thickness. The Re-Ni-Cr DBC showed some reaction with Ni22Cr-10Al-1Y (wt\%) coating and Haynes 214, forming a Crrich phase that was inferred to be $\alpha$-Cr. The thick ( $\sigma$-based) DBC was effective in limiting coating/substrate interdiffusion.

The high-energy mill $\sigma$-powder fabrication followed by the HVOF deposition of that powder is considered to be an effective DBC processing route. Moreover, this route provides the latitude to deposit a range of Al-reservoir overlays, such as the NiCrAlY used in the FY11 study.

\section{Micro-Indentation Stiffness Evaluation of Thermal Barrier Coated Materials}

As a viable research tool, a high temperature micro-indentation test facility was successfully designed and constructed at WVU for determining TBC material properties (i.e., stiffness) during extended exposure at high temperature in air and steamcontaining environments. Preliminary tests were conducted for both in-situ high temperature and room temperature stiffness measurements of René N5/MCrAlY/APS TBC coupons during cyclic oxidation testing in air at $1100^{\circ} \mathrm{C}\left(\sim 2010^{\circ} \mathrm{F}\right)$. Test results revealed an increase of surface stiffness due to possibly sintering of the top coat during the initial thermal exposure, followed by a reduction in stiffness which is currently attributed to strength degradation of the 7-8YSZ as microcracking occurs during continued thermal cycling. Notably, surface stiffness measurements at $1100^{\circ} \mathrm{C}\left(\sim 2010^{\circ} \mathrm{F}\right)$ are $>50 \%$ lower than stiffness measurements determined at room temperature, indicating the influence of temperature on coating system material properties.

\section{ACKNOWLEDGMENTS}

We acknowledge Mr. Richard Dennis, DOE NETL Turbine Technology Manager, for his technical support. Efforts are being performed under the NETL Contract DE-FE0004000.5.622.243.001/002.

Tests and metallographic preparations conducted by Dr. Nan $\mathrm{Mu}$ at the University of Pittsburgh, now at the National Center for Materials Service Safety (NCMS) in China, are gratefully acknowledged. We additionally acknowledge Mr. Jeffery Colston and Mr. Ken Murphy at Howmet International for application of the APS YSZ TBC coatings. The efforts of Dr. Minking Chyu, Mr. Sean Siw, Dr. Pavin Ganmol, Dr. Srinath Ekkad, Mr. Chris LeBlanc, Dr. Karen Thole, and Dr. Michael Barringer are acknowledged for their contributions to the heat transfer and secondary flow technology development aspects of this project.

\section{REFERENCES}

1. Current and Future Technologies for Gasification-Based Power Generation, Volume 2: A pathway Study Focused on Carbon Capture Advanced Power Systems R\&D Using Bituminous Coal, November 25, 2009, DOE/NETL2009/1389.

This material is declared a work of the U.S. Government and is not subjected to copyright protection in the United States.

Approved for public release; Distribution is unlimited. 
2. R.A.Dennis, FE Research Direction - Thermal Barrier Coatings and Health Monitoring Techniques, Workshop on Advanced Coating Materials and Technology for Extreme Environments, Pennsylvania State University, State College, PA, September 12 - 13, 2006.

3. B. Gleeson, Journal of Propulsion and Power, 22, 375 (2006).

4. W.Schlacter, G.H.Gessinger, in E.Bachelet, et al (Eds.) High-Temperature Materials for Power Engineering, Kluwer Academic Publishers, Dordrecht, 1990, p.1.

5. M. Konter and M.Thumann, Materials and Manufacturing of Advanced Industrial Gas Turbine Components, J. Materials Processing Technologies, Vol. 117, Issue 3, November 23, 2001, P.386-390.

6. Prof. Toshio Narita, Hokkaido University, Japan, communications with Brian Gleeson.

7. J.Tannenbaum, K.Lee, B.Kang, and M.A.Alvin, NonDestructive Spallation Prediction of Thermal Barrier Coatings by a Load-Based Micro-Indentation Technique, Materials Science and Technology 2010, Houston, TX, October 17-21, 2010.

8. J.Tannenbaum, C.Chou, B.Kang, and M.A.Alvin, A Portable Load-Based Micro-Indentation Technique for OnSite Mechanical Property Evaluation of Structural Components, Materials Science and Technology 2010, Houston, TX, October 17-21, 2010.

9. J.Tannenbaum, K.Lee, B.Kang, and M.A.Alvin, NonDestructive Thermal Barrier Coating Spallation Prediction by a Load-Based Micro-Indentation Technique, 2010 ASME International Mechanical Engineering Congress and Exposition, Vancouver, British Columbia, Canada, November 12-18, 2010.

10. K.Lee, J.Tannenbaum, B.Kang, and M.A.Alvin, A LoadBased Depth-Sensing Indentation Technique for ElasticPlastic Material Mechanical Property Evaluation, 2010 ASME International Mechanical Engineering Congress and Exposition, Vancouver, British Columbia, Canada, November 12-18, 2010.

11. J.Tannenbaum, K.Lee, B.Kang, and M.A.Alvin, An Indentation Based Non-Destructive Evaluation Technique for Thermal barrier Coating Spallation Prediction, $35^{\text {th }}$ International Conference and Exposition on Advanced Ceramics and Composites, Daytona Beach, FL, January 23-28, 2011.

12. J.Tannenbaum, K.Lee, B.S.-J. Kang and M.A.Alvin, Material Performance of TBCs in High Temperature Moisture-Containing Environments Using a Load-based Micro-indentation Technique, TMS Annual Meeting \& Exhibition, San Diego, CA, February 27 - March 3, 2011.

13. J.Tannenbaum, B.S.-J.Kang and M.A.Alvin, The Development of a Non-Destructive Multiple Partial Unloading Micro-Indentation Technique for Thermal Barrier Coating Spallation Prediction, TMS Annual Meeting \& Exhibition, San Diego, CA, February 27 March 3, 2011.
14. J.Tannenbaum, B.S.Kang and M.A.Alvin, Material Performance of TBC Systems at High Temperature in Moisture Rich Environments Using a Load-Based MicroIndentation Technique, ASME 2011 International Mechanical Engineering Congress \& Exposition, Denver, CO, November 11-17, 2011.

15. K.Lee, J.Tannenbaum, B.S.Kang and M.A.Alvin, A LoadBased Depth-Sensing Indentation Technique for ElasticPlastic Material Mechanical Property Evaluation: Numerical and Experimental Investigation, ASME 2011 International Mechanical Engineering Congress \& Exposition, Denver, CO, November 11-17, 2011.

16. B.Kang, J.Tannenbaum and M.A.Alvin, TBC System Performance in Simulated Land-Based Gas Turbine Environments Using a Load-Based Micro-Indentation Technique, MS\&T Conference, Columbus, OH, October 16-20, 2011.

17. K.Lee, J.Tannenbaum, B.Kang and M.A.Alvin, A Multiple Partial Unloading Indentation Technique for ElasticPlastic Mechanical Property Evaluation: Numerical and Experimental Investigation, MS\&T Conference, Columbus, OH, October 16-20, 2011.

18. S.Siw, M.Chyu, and M.A.Alvin, Heat Transfer Enhancement of Internal Cooling Passage with Triangular and Semi-Circular Shaped Pin-Fin Arrays, ASME Turbo Expo, Copenhagen, Denmark, June 11-15, 2012 (GT201269266).

19. S.Siw, M.Chyu, and M.A.Alvin, Investigation of Heat Transfer Enhancement and Pressure Characteristics of Zig-Zag Channel, ASME Turbo Expo, Copenhagen, Denmark, June 11-15, 2012 (GT2012-69268).

20. C.LeBlanc, S.Ekkad, and M.A.Alvin, Flow Visualization and Film Cooling Effectiveness of Tripod Antivortex Injection Holes on a Flat Plate, ASME Turbo Expo, Copenhagen, Denmark, June 11-15, 2012.

21. K.Thole and M.Barringer, Development of a Rotating Turbine Rig at Penn State to Study Secondary Flow Leakages and Aerothermal Cooling, UTSR Conference, September 25-27, 2011, Columbus, OH.

This material is declared a work of the U.S. Government and is not subjected to copyright protection in the United States. Approved for public release; Distribution is unlimited. 